\title{
School personnel's perceptions of their schools' involvement in culturally and linguistically diverse school-family-community partnerships
}

\section{BACKGROUND}

The achievement gap between White and culturally and linguistically diverse (CLD) students is a chronic issue in many U.S. schools that stakeholders endeavor to eliminate through best practices involving curriculum, instruction, and early interventions; however, disparities often persist. In addition to all educational efforts provided by schools and implementation of best practices when students begin to struggle academically or behaviorally in schools, family involvement cannot be disregarded.

\section{PARTICIPANTS AND PROCEDURE}

School personnel from one Midwestern school district in the United States educating over 8,000 students was surveyed to obtain their perceptions about school-family-community partnerships. A total of 117 informants, including teachers, student support personnel, and administrators, provided their opinions through an online survey measuring responses to questions related to current best practices in their schools with regard to culturally and linguistically diverse students, their families and their communities.

\section{RESULTS}

In a research study focused on school practices relating to parent involvement, it was found that strategies intend- ed to encourage and incorporate parent involvement were implemented in just one-third to one-half of the schools surveyed, indicating the need for increased and concerted effort on the part of school professionals to recognize and address obstacles to a pivotal school-parent-community relationship.

\section{CONCLUSIONS}

Although schools can be credited with endeavoring to provide best practices for their CLD students, in keeping with state and federal mandates and assumedly in keeping with best intentions, there is in fact much work to be done to better facilitate the success of these students. School psychologists can provide the impetus for this effort by formally recommending parent involvement and participation in their assessments of CLD students in particular. This recommendation should inherently include awareness and consideration of cultural preconceptions that may hinder parent involvement.

\section{KEY WORDS}

cultural diversity; linguistic diversity; parent involvement; school communication

ORGANIZATIONS - Northeastern Illinois University, Chicago, IL, USA

AUthors' CONTRIBUtion - A: Study design - B: Data collection - C: Statistical analysis - D: Data interpretation .

E: Manuscript preparation · F: Literature search · G: Funds collection

CORRESPONDING AUTHOR - Jolanta Jonak, Ed.D., Northeastern Illinois University, 5500 N. St. Louis Ave., LWH-4020B,

Chicago, IL 60625, USA, tel. 773-442-5992, e-mail: j-jonak@neiu.edu

TO CITE THIS ARTICLE - Jonak, J. (2014). School personnel's perceptions of their schools' involvement in culturally

and linguistically diverse school-family-community partnerships. Health Psychology Report, 2(1), 19-26.

DOI: $10.5114 /$ hpr.2014.42788 


\section{BACKGROUND}

Often despite best school efforts to intervene and address the issue of student low achievement, some students continue to struggle academically, socially, or emotionally. This is partially attributable to linguistic diversity and cultural diversity of perspectives rooted in family and community. The achievement gap between White and minority students is a chronic issue in many U.S. schools that stakeholdJolanta Jonak ers endeavor to eliminate through best practices involving curriculum, instruction, and early interventions; however, disparities often persist. In addition to all educational efforts provided by schools and implementation of best practices when students begin to struggle academically or behaviorally in schools, family involvement cannot be disregarded. If there is no successful school-family partnership, each child is seen as a "school child and home child, ignoring the whole child" (Epstein, 2001, p. 5). School-family-community partnership takes place when "educators, families, and community members work together to share information, guide students, solve problems, and celebrate successes" (Epstein, 2001, p. 4). It is very important that educators and mental health professionals appreciate and incorporate the contexts in which students live, work, and play because without such understanding "educators work alone, not in partnership with other important people in students' lives" (Epstein, 2001, p. 5). Often it is the school psychologist who is the linchpin in student interventions; school psychologists can and should incorporate parent-community involvement as appropriate in their standard assessments and recommendations.

Even No Child Left Behind (NCLB), a federal legislation meant to accomplish standard-based education reform, requires school-home collaboration. Schools that are using Title III (legislation regarding language instruction for limited English proficient and immigrant students) funds must employ effective methods of outreach to parents of ELL (English language learners) children and they must inform parents about ways of becoming active participants in assisting their children in learning English. Such schools and their students have high achievement levels in core academic subjects and meet state standards (National Coalition for Parent Involvement, n.d.).

Unfortunately many educators and mental health professionals are not prepared adequately to work positively and productively with students' families, nor have they had prior formal education in school, family, and community partnerships (Epstein, 2001). Many education professionals work with their students without "adequately understanding the backgrounds, languages, religions, cultures, histories, structures, races, social classes or other characteristics of their students or families" (Epstein, 2001, p. 5).
Epstein (2001), an expert in school-family-community partnerships, states that without an understanding of these factors, it is unfeasible for school personnel to communicate effectively with students' families. She further provides a conceptual framework recommending that all education professionals need to understand the surrounding community, the home communities of their students, and local businesses and organizations that can enrich and extend student education (2001). A school-family-community partnership is recommended best practice for general school situations, but an appropriately developed model will also include minorities, culturally and linguistically diverse families, special education families, and families that are otherwise hard to reach.

Involvement of parents from different cultures and languages is at least as important in the process of education as the involvement of any other parents. Although some education professionals may prefer to have a minimal relationship with their students' parents, such relationships are undoubtedly crucial for enhancing student success and emotional wellbeing.

However, even when schools are trying to increase parental involvement, often they are unsuccessful. This problem is more conspicuous with culturally and linguistically diverse (CLD) parents from low-income households (Burnette, 1998). A very prevalent assumption for CLD parents' lack of involvement is lack of caring on their part. However, involvement of parents from diverse cultural and linguistic backgrounds may be impeded by various factors such as: being unaware of the schools' expectations of them and their role in this process; frustrations due to language and cultural differences; childcare and transportation difficulties; and/or lack of time available (Burnette, 2000). Some parents may have had negative experiences in school - possibly related to these factors - and may be reluctant to meet with educators or they may have little formal education and feel unqualified to contribute (Burnette, 1998). Mitylene and Lassmann (2003) state that parents who did not have positive public school experiences themselves "are not willing participants in the public education process, and are suspicious of school-based activities in which they do not participate" (p. 1). The following quote can summarize the need for family involvement:

When societal conditions do not permit positive orientations between home and school, minority students come to school already predisposed to failure, a situation exacerbated by parents' limited access to economic and educational resources, bicultural ambivalence, and interactional styles that may not facilitate successful teacher student interactions in the classroom (Heath, 1983; Wong-Fillmore, 1983, as cited in Ortiz, 1992, p. 4).

Since there are numerous factors that inhibit CLD parental involvement in the education of their children, it is important that schools and mental health 
professionals collaborate toward the goal of reaching out to families to make the partnership more effective. Burnette (1998) suggests the following in order to improve CLD family-school partnership: first, identify and address obstacles to parent participation and offer school staff compensatory time for facilitating parent availability for meetings; second, provide options for involvement that are matched to families' motivations, interests, and abilities and make sure that families are aware of the many ways they can support the education of their children; additionally, ensure that the school is welcoming, accessible, understanding and respectful of diverse family networks and child-rearing traditions including family members beyond the nuclear family who are involved in daily child rearing.

Burnette (1998) also recognized that it is important to make parents and families aware of the roles and responsibilities expected of them in the school; these may differ from their roles and responsibilities in their own cultures. In addition to effectively and consistently implementing federal and state mandates for parent involvement, educators and mental health professionals must communicate in ways that convey respect and appreciation for cultural differences. Finally, Burnette recognized that school systems should translate documents for families who do not communicate easily in English language.

In their work with the Office of Special Education Programs (OSEP) to identify the best referral and decision-making process for culturally and linguistically diverse students, Harry and Klinger found that existing special education overrepresentation of minority students might be due to family and community factors, among other issues (Warger \& Burnette, 2000). They propose that in order to prevent inappropriate referrals and placements into special education programs, it is important to promote family involvement and respect diverse backgrounds. Learning from families' cultures as much as possible (Warger \& Burnette, 2000) can be beneficial for both students and schools. The importance of understanding cultural differences and its potential impact on student progress cannot be underestimated.

An appropriate and dynamic identification process encompasses the local community, school, and classroom (Skiba et al., 2003, p. 9). Including parent and community consideration as well as collaboration with classroom teachers can contribute significantly to the efficacy of the assessment practices of academic and mental health professionals. In order to effectively help CLD children, the field of education needs to include a school-family-community partnership in its range of best practices. Through honest attempts in encouraging school-family partnership, the CLD families may assist in extending this partnership into their communities. Through such comprehensive approaches to education and student success support, the potential for improved desired outcomes tremendously increases.

"Collaboration with Culturally and Linguistically Diverse Families: Ideal Versus Reality”, written by Beth Harry (2008) of the University of Miami, reviews current literature in ideal and current practices of CLD needs and families. Referenced in this resource is the requirement that educational institutions must identify, recognize, and assist in needs defined under the Individuals with Disabilities Educational Act (IDEA) (Harry, 2008). Individuals with Disabilities Educational Act also requires educational institutions to maintain clear and successful communication with families of students in these programs, which Harry identifies as essential to maintaining quality education for CLD needs, clarifying that CLD families may have widely varying communication needs (2008).

The studies reviewed by Harry demonstrate that there are often imbalances in the number of children identified by IDEA needs; additionally, the groups able to receive interventions or understand the available methods for which interventions can take place are most often of a different cultural background than the majority of the group or team providing the assistance (Harry, 2008). Much of the development of this report had a basis in the home-service options for CLD needs, even defining best practices for caregivers for disability needs. However, it is important to note that school-family relationships are often dampened by the inability of families to go to the school, or the uncomfortable feelings that CLD families may have with the language barrier that makes relationships with school personnel unreliable and trying. Finally, Harry (2008) recognizes that "Caregivers who have participated in such studies have made it clear that their vision is one of respect and support... Yet, attainment of these goals remains elusive for many CLD families" (p. 383).

Poor communication practices between schools and families may be a factor contributing significantly to CLD students not receiving the benefits of the very strategies designed for their academic achievement. Poor communication and collaboration may further impede families' active participants in their children's education, identification of their needs, and solicitation of support from school and/or community programs. Such practices may have a direct adverse impact on students' perceptions about their own value and importance, which is directly connected to their self-esteem and not only academic but also emotional wellbeing.

\section{PARTICIPANTS AND PROCEDURE}

The author developed and implemented a survey research instrument entitled CLD Students and Their
Perceptions of school-familycommunity partnerships 
Educational Opportunities, measuring education professionals' responses to questions related to current best practices in their schools with regard to CLD students, their families and their communities.

A careful and informed practice guided the development of this instrument. Research methodology was based on quantitative research guided by descriptive research which aims at "discovering the interrelationships among the dimensions of a problem, describing them, and determining the cause-and-effect direction of the relationships if possible" (Asher, 1976, p. 134). It also allows studying a "phenomenon as it is occurring naturally, without any manipulation or intervention" (Ravid, 2005, p. 5), making it a good fit for the purpose of this study.

The design of this research instrument was guided by recommended best practices in the survey research domain, best practices identified in the field of bilingual and special education, and consultation with expert researchers. Epstein's framework of family-school-community partnership is one of the most widely accepted in the field and serves as an important theoretical foundation for practice and research. It stresses the importance of collaboration between these three domains to enhance students' development and learning (Epstein, 2001). Many aspects of this theoretical underpinning were used to develop this survey.

Although the scope of the study was geographically narrow, the survey respondents comprised a representative population. For this study, participants were selected from the school district of an urban county in the upper northeastern section of the state of Illinois which includes and surrounds the Chicago metropolitan area. The county has a population of approximately 5.3 million people, the second most populous county in the nation (ePodunk, 2008), and was selected for this study due to being composed of culturally and linguistically diverse communities. From this county, one southwestern high school district was selected to participate in this study. This community was selected for this study due to its linguistic, cultural, and economic diversity.

According to the 2000 Census, this district's total population is over 156,000 , including nearly 90,000 individuals of Hispanic or Latino background, and a non-White alone population of over 96,000, of which, under the age of eighteen, the total population of Hispanics and Latinos is nearly 48,000, and the total non-White alone is 37,000 (U.S. Census Bureau, 2000). This school district educates over 8,000 students. In the district's student body $13 \%$ are White, $2 \%$ are African-American, 83\% Hispanic, $1 \%$ Asian/Pacific Islander, $0.1 \%$ Native American, and less than $1 \%$ multiracial. The teaching body is composed of nearly $87 \%$ White, $1 \%$ African-American, $10 \%$ Hispanic, and 2\% Asian/Pacific Islander.

Respondents to the statements below numbered 117 from a total of 143 participants in the entire sur- vey, which represented three schools within the same district. The largest respondent group was that of regular education teachers with $62 \%$, followed by special education teachers $(15 \%)$, related service personnel (14\%), administrators (6\%), and ESL/bilingual teachers (3\%). Respondent groups were nearly equally split among degree levels until the doctoral level, where under 3\% of respondents were represented. Many of the respondents, approximately $75 \%$, answered that they had taken courses either within the past year or past three years. Additionally, these participants typically have between zero to five years' experience in their field (38\%), and less than five years' experience within their school district (44\%). The majority of the participants responded that they are Caucasian (87\%). Hispanic participants accounted for $11 \%, 1.5 \%$ identified themselves as African American, and less than $1 \%$ identified themselves as "other". Finally, $65 \%$ of respondents only speak one language.

The purpose of this study was to investigate quantitatively to what extent surveyed participants report district efforts to improve family-school partnerships. This question evaluated whether the school districts surveyed actively involve CLD students' families and to what extent. Survey questions and responses below, excerpted from the entire survey, frame key practices associated with parent and community involvement of CLD students. Responses were subjective, based on participants' awareness and perceptions of practices within their school.

Participants were asked to respond to the following questions, in the form of statements, with "always", "often", "sometimes", "rarely", or "never". Data represent percentages of the 117 respondents. The statements were:

1) Your school takes every effort to increase schoolfamily partnership.

2) Your school provides parents and families with information about their rights and responsibilities.

3) Your school identifies and addresses obstacles to parent participation.

4) Your school provides options for family involvement.

5) Your school educates families on how they can support their children's education.

6) Your school communicates with respect and appreciation for cultural differences.

7) Your school translates documents for families who speak languages other than English.

\section{RESULTS AND DISCUSSION}

The results of this study were developed to examine critical components in responses as they apply to uniquely different respondents, which may indicate areas where resolutions to concerns can be applied. A discussion of the results included the relationship 
Table 1

Participants' reports on district's efforts to improve family-school-community partnerships

\begin{tabular}{|c|c|c|c|c|c|c|c|}
\hline $\begin{array}{l}\text { Frequency } \\
(\text { Avg \%) }\end{array}$ & $\begin{array}{c}\text { Takes } \\
\text { efforts } \\
\text { to increase } \\
\text { school- } \\
\text { family } \\
\text { partnerships }\end{array}$ & $\begin{array}{c}\text { Provides } \\
\text { parents } \\
\text { and } \\
\text { families } \\
\text { with } \\
\text { information }\end{array}$ & $\begin{array}{c}\text { Identifies } \\
\text { and } \\
\text { addresses } \\
\text { obstacles } \\
\text { to parent } \\
\text { participation }\end{array}$ & $\begin{array}{l}\text { Provides } \\
\text { options } \\
\text { for } \\
\text { family } \\
\text { involve- } \\
\text { ment }\end{array}$ & $\begin{array}{c}\text { Educates } \\
\text { families on } \\
\text { how they } \\
\text { can support } \\
\text { child's educ. }\end{array}$ & $\begin{array}{l}\text { Respect } \\
\text { and } \\
\text { apprec. } \\
\text { for } \\
\text { cultural } \\
\text { diff. }\end{array}$ & $\begin{array}{l}\text { Trans- } \\
\text { lation } \\
\text { of docs }\end{array}$ \\
\hline $\begin{array}{c}\text { Always } \\
(29 \% \text { avg.) }\end{array}$ & 22 & 28 & 19 & 22 & 25 & 39 & 50 \\
\hline $\begin{array}{c}\text { Often } \\
\text { (33\% avg.) }\end{array}$ & 37 & 31 & 31 & 33 & 31 & 32 & 36 \\
\hline $\begin{array}{c}\text { Sometimes } \\
(26 \% \text { avg.) }\end{array}$ & 27 & 32 & 32 & 33 & 28 & 20 & 12 \\
\hline $\begin{array}{c}\text { Rarely } \\
\text { (10\% avg.) }\end{array}$ & 12 & 8 & 14 & 11 & 15 & 9 & 1 \\
\hline $\begin{array}{c}\text { Never } \\
(2 \% \text { avg.) }\end{array}$ & 3 & 2 & 5 & 2 & 2 & 2 & 1 \\
\hline
\end{tabular}

to findings in the literature review and a review of the extent to which surveyed participants report efforts to improve family-school partnerships.

Survey participants were asked about their perceptions on the district's efforts to improve family-school-community partnerships. Specifically they were asked about a) their district's efforts to increase school-family partnerships, b) providing parents and families with information about their rights and responsibilities, c) identifying and addressing obstacles to parent participation, d) providing options for family involvement, e) educating families on how they can support their child's education, f) respecting and showing appreciation for cultural differences, and g) translating documents for families who speak languages other than English.

The Table 1 encapsulates the responses, expressed in percentages.

In developing sustainable family-school partnership practices, it is important to employ and facilitate parental involvement and participation as they are significant in establishing practices that support learning for all students (Daniel, 2011). In this survey, results show evidence of some encouraging practices, but at the same time there is clear indication that further enhancement is desired. Although the percentages are generally encouraging in that "rarely" and "never" represent a mere $10 \%$ of the responses on average, note must be taken that "always" garnered less than one-third of the responses, with a particularly low $19 \%$ for "identifies and addresses obstacles to parent participation".

LaRocque (2013) identifies two types of parental involvement, external and internal, where external involvement includes activities outside the home and in the school and internal involvement includes atti- tude towards education and ability to assist children with schoolwork. Schools should accept the challenge to determine which type of parental involvement is lacking and how they can remediate this problem. Involvement of parents from diverse cultural and linguistic backgrounds may be impeded by various factors like not being aware of the schools' expectations of them and their role in this process, frustrations due to language and cultural differences, childcare and transportation difficulties, or lack of time (Burnette, 2000; LaRocque, 2013).

Over $20 \%$ of respondents felt that the school "always" "takes every effort to increase school-family partnership"; however, this small percentage of respondents is particularly concerning based on the requirements that schools using Title III federal funds must employ effective methods of outreach to parents of English Language Learning children, and must inform parents about ways of becoming active participants in assisting their children in learning English. In addition, the following are also best practices that schools can use to reach families: support parent-to-parent advocacy such as Title I (federal financial assistance designated to help schools with high numbers of low-income and disadvantaged families to ensure that all students achieve high academic standards) liaison activities, communicate in ways that convey respect and appreciation for cultural differences, and translate documents for families who do not communicate easily in English. When schools recognize that there are families unable or unwilling to participate in the relationship, they should actively seek understanding of where the problem may exist in order to better reach the needs of these families.

Also, less than one-third of participants, only $28 \%$, felt that their school "always" "Provides parents and
Perceptions of school-familycommunity partnerships 
families with information about their rights and responsibilities". As mentioned previously, schools are required to do this. Often this requirement can be difficult when the school is unaware of the language issues at home; however, providing this information is essential to quality relationships between school and family. Some immigrant families may be reluctant to take a leading role in educating their child as such a close partnership with school may not be a familiar role (LaRocque, 2013). In his 2003 work, Ramirez found that some parents did not feel that it was appropriate to be involved in their child's classroom unless they received a personal invitation (LaRocque, 2013). This is clear evidence that parental perception of what is considered appropriate involvement is rooted in cultural backgrounds. Effective ways to increase the involvement may begin with solving the perceived problems of information transfer to the home and increasing the awareness of family responsibilities and rights.

Data from the survey indicate that while 39\% always communicate with respect and appreciation for cultural differences, and an encouraging $50 \%$ translate documents for families who speak languages other than English, less than one-third of the respondents reported that their schools provided parents and families with information about their rights and responsibilities. This can further widen the chasm between schools and parental involvement, if parents are not aware of their rights regarding their low achieving children and how they should assist them. The school should be cognizant about not only translating documents, but also the use of domain-specific and complicated language. Education-specific language and acronyms may be confusing, intimidating, and overwhelming for any parent. When students have disabilities, the language is even more intensified and difficult for parents (LaRocque, 2013). Although accurate terminology is necessary and often required by state and federal regulations, the ultimate goal should be to communicate important aspects and create necessary support systems for students. Moreover, schools and families need to recognize that "mutual misconceptions and misunderstandings, stereotypes, intimidation and distrust undermine efforts to increase parental involvement" (LaRocque, 2013, p. 114).

The aggregate data indicate that just over $50 \%$ of the respondents reported that their schools "always" or "often" followed best practices with respect to encouraging and facilitating school-family partnerships for CLD students. Still nearly half of respondents did not endorse this as systematic practice. Research indicates that some culturally and linguistically diverse families signify meager understanding of how to navigate the school system and how to effectively work with their children's schools (Anderson, 1994; Harry, 1992; Rao, 2000, as cited in LaRocque, 2013). Therefore, schools should think of creative ways to help families navigate the school system and make these efforts systematic. These efforts should be sensitive to given community needs, cultural backgrounds, language proficiencies, parental previous educational experiences, and parental schedules, just to name a few. Schools could host various events during and outside of school to facilitate the sense of community that works towards a mutual goal, which is the students' success. It is imperative for schools to identify potential practices that they may in some ways include or exclude families from diverse backgrounds (Daniel, 2011).

These results demonstrate that there is much work that could be done to improve the family-school relationship, based on key points addressed from Burnette's (1998) descriptions of best practices. Daniel signifies that "when family-school partnerships are integrated as an everyday embodied practice within the curriculum, students' existing socio-culturally based understandings and knowledges become part of the learning environment" (2011). It is also essential to create value for families of CLD students due to the potential for special education overrepresentation as it may be related to family and community issues, in addition to school-related situations (Warger \& Burnette, 2000)

\section{CONCLUSIONS}

School systems are concerned with educating all students and obtaining best outcome results. Epstein indicates that numerous studies show that teachers, parents, administrators, and students agree that involvement benefits students, improves schools, assists teachers, and strengthens families (2001). Teachers need to understand, design, select, conduct, and evaluate connections with individuals and groups in communities to maximize learning opportunities in all academic areas, family life (Epstein, 2001), and social emotional wellbeing. There are many stakeholders involved in this process, and it is essential that various stakeholders are engaged meaningfully. Children, families and their entire communities are important stakeholders that are sometimes undervalued by school systems. Although schools can be credited with endeavoring to provide best practices for their CLD students, in keeping with state and federal mandates and assumedly in keeping with best intentions, there is in fact much work to be done to better facilitate the success of these students. Primarily, issues identified by school professionals as hindering parent participation may be based on partial if not incorrect assumptions.

Education of students involves a multifaceted approach that should be aided by knowledge, expertise, and engagement of concerned stakeholders. Mental health professionals, mainly school psychologists, in particular are in a position to help identify obstacles 
to parent participation in student assessment and achievement, by recommending that intervention for low-achieving students, and particularly CLD students, include the collaborative and concerted efforts of school staff to inform parents of their rights and responsibilities, include families in success strategies, and most importantly, be open to different modes of being accessible for parent communication.

\section{RECOMMENDATIONS}

"It is important that educators understand that parents represent our nation's diversity and parental participation can also be diverse" (LaRocque, 2013). Well-designed programs and practices in school, family, and community partnerships benefit students, families, and schools (Epstein, 2001). Teachers and administrators have direct or indirect contact with students' families everyday (Epstein, 2001); therefore it is imperative that they recognize the importance of effective school-home collaboration and that they are adequately prepared to work with them. Enhanced collaboration approaches between home, school, and community are hoped to have beneficial impacts not only on students' academic achievements, but also on their social emotional growth and ultimately increased chances for successful lives. LaRocque recommends that educators should expand the definition of what is considered as "acceptable forms of participation to include ways that are more comprehensive, varied, and reflective of how families are able to participate" (2013, p. 116).

Information gained directly from the engaged school professionals is tremendously valuable as it presents the current situation or perceptions of the current situation. School administration should use such data for self-evaluation and to outline areas needing improvement. All school staff should implement at least informal self-evaluation practices in the area of facilitating parent involvement of CLD students. Instead of just employing a few strategies that favor the goal of improving parent participation, school professionals should critically assess their practices vis-à-vis the actual incidence of participation, and ask themselves how they can better encourage and facilitate parent participation particularly in CLD student academic and non-academic achievements. Research indicates that these self-evaluation practices will result in higher student success rates and therefore more effective results of the strategies that are already in place (National Coalition for Parent Involvement, n.d.).

Mental health professionals, especially school psychologists, due to their unique roles, should both encourage and formally recommend parent involvement and participation in their assessments of CLD students in particular. This recommendation should inherently include awareness and consideration of cultural preconceptions that may hinder parent involvement. In their role of student liaison, they have an ethical obligation to ensure that the whole student, including cultural expectations and reservations, be incorporated in their assessments.

School psychologists are often engaged in the development and implementation of school improvement plans, making them the ideal agents to cause the necessary changes in regards to the wide-ranging involvement of all stakeholders, especially the often-overlooked family and community partners. School systems need to have a confidence and conviction that long-lasting and positive school-family partnership will improve academic, behavioral, and social-emotional outcomes for children. School systems need to see themselves as open systems that are nested between families and communities within the ecological system. Such a paradigm will ensure positive and effective learning communities where all expertise is welcomed for the purpose of having the most effective school experiences for all students. Due to the ever-growing globalization framework present not only in the United States but also around the world, educational systems must engage in practices that are collaborative and reflective of the changing world in which our children live.

\section{RefERENCES}

Asher, W. (1976). Educational Research and Evaluation Methods. Boston: Little, Brown and Company.

Burnette, J. (1998). Reducing the disproportionate representation of minority students in special education. ERIC/OSEP Digest, \#E566, ERIC Clearinghouse on Disabilities and Gifted Education, Council for Exceptional Children. Retrieved, from http://eric.ed.gov/ERICDocs/data/ericdocs2sql/ content_storage_01/0000019b/80/15/4e/26.pdf

Burnette, J. (2000). Assessment of culturally and linguistically diverse students for special education eligibility. ERIC Clearinghouse on Disabilities and Gifted Education Arlington VA. (ERIC Document Reproduction Service No. ED449637).

Daniel, G. (2011). Family-school partnerships: towards sustainable pedagogical practice. Asia- $\mathrm{Pa}$ cific Journal of Teacher Education, 39, 165-176. doi: 10.1080/1359866X.2011.560651.

ePodunk.com. (2008). Cook County, IL, ancestry and family history. Retrieved from http://www. epodunk.com/cgi-bin/genealogylnfo.php?loclndex $=6032$

Epstein, J. (2001). School, family, and community partnerships: Preparing educators and improving schools. Boulder, Colorado: Westview Press.

Harry, B. (2008, Spring). Collaboration with culturally and linguistically diverse families: Ideal ver-
Perceptions of school-familycommunity partnerships 
sus reality. Exceptional Children, 74, 372-388. Retrieved from MasterFILE Premier database.

LaRocque, M. (2013). Addressing Cultural and Linguistic Dissonance Between Parents and Schools. Preventing School Failure, 57, 111-117. doi:10.1080/ 1045988X.2012.677961.

Mitylene, A. \& Lassmann, M. (2003, Winter). Overrepresentation of minority students in special education. Education, 124, 230-237. Retrieved from http://niusi.edreform.net/resource/17689.

Jolanta Jonak

National Coalition for Parent Involvement. (n.d.). $N C L B$ action briefs, programs of English language learners. Retrieved from http://www.ncpie.org/ nclbaction/english_language_learners.html.

No Child Left Behind Act of 2001. PL 107-110, 115 Stat. 1425.

Ortiz, A. (1992, August). Assessing appropriate and inappropriate referral systems for LEP special education students. Focus on evaluation and measurement. Vol. 1-2. Proceedings of the National Research Symposium on Limited English Proficient Student Issues. Washington, DC. (September 4-6, 1991).

Ravid, R. (2005). Practical statistics for educators. $3^{\text {rd }} \mathrm{ed}$. Lanham, MD: University Press of America.

Skiba, R.J., Simmons, A.B., Ritter, S., Kohler, K., Henderson, M. \& Wu, T.C. (2003). The context of minority disproportionally: Local perspectives on special education referral. Bloomington, IN: Indiana University, Indiana Education Policy Center.

U.S. Census Bureau. (2000). 2000 Census bureau report. Retrieved from http://www.census.gov/ main/www/cen2000.html and http://www.census. gov/population/www/cen2000/briefs/phc-t20/tables/tab05.pdf.

Warger, C. \& Burnette, J. (2000). Five strategies to reduce overrepresentation of culturally and linguistically diverse students in special education. Retrieved from ERIC/OSEP Digest \#E596, ERIC Clearinghouse on Disabilities and Gifted Education http://www.ericdigests.org/2001-3/five.htm 